\title{
Comfortable living environment as the basis for rural development in the mining region
}

\author{
Piotr Kosinskiy ${ }^{1, *}$, Aleksey Kharitonov $^{1}$, Eduard Wolfson ${ }^{1}$, and Rimma Takhtayeva ${ }^{2}$ \\ ${ }^{1}$ T. F. Gorbachev Kuzbass State Technical University, 28 Vesennyaya, Kemerovo, 650000 \\ ${ }^{2}$ Kazakh Humanitarian and Legal Innovation University, Semey City, Republic of Kazakhstan
}

\begin{abstract}
The article is devoted to the study of the problems of mining industry development and its impact on the development of rural areas in the region. It is revealed that the intensive development of the mining industry is accompanied by negative environmental consequences associated with the impact on socio - economic development and the formation of a comfortable living environment and, as a result, the quality of life of the population of rural areas. The Kemerovo region characterized by a pronounced intensive development of the coal industry accompanied by air pollution, rejection of land with high fertile potential, and degradation of renewable natural resources. The activities of mining companies accompanied by the release of highly toxic and carcinogenic substances into the air. As a result, there is an increased morbidity and mortality of able-bodied residents of the region, a low life expectancy, and a decrease in the total rural population, which is faster than the urban population. To solve the identified problems, the author's model of creating a comfortable living environment in the mining region proposed. The model makes it possible to assess the attractiveness of the territory when deciding on the future place of residence, and, also allows you to make informed management decisions aimed at improving the quality of life of people.
\end{abstract}

\section{Introduction}

A comfortable living environment for people is not only determining when choosing a future place of residence, but also an important component of the quality of life of the population. The settlement of a certain territory influenced by factors such as the environment and the state of its cleanliness, environmental safety, which form a comfortable environment for people to live in.

The ability to meet the needs for clean air, the presence of favorable natural and climatic conditions, the available recreational resources that form comfort and attractiveness when choosing a place of residence determine the direction of migration flows. Pollutants of the natural environment, anthropogenic load on the population are components that repel people and minimize their desire to live in such a territory.

\footnotetext{
* Correspondent author: kpd.gimu@kuzstu.ru
} 
At the same time, these reasons are not always decisive when choosing a place of residence. In many cases, economic factors come to the fore: higher wages, conditions that promote employment, but are a source of creating a negative environment for living, reflected by an increased level of morbidity of residents. It is well know that an important indicator that characterizes the quality of life of the population is its health, on which life expectancy largely depends.

The greater significance of the indicator describing health accompanied by a longer life expectancy, which means the most comfortable environment for living. The indicator that characterizes the health of the population is not an integral one, but it is without exaggeration a key indicator in assessing its quality of life.

The purpose of the work is to study the state of comfortable living environment as the basis for the development of rural areas in the mining region and to model the improvement of its formation.

The study of the impact of the mining industry on a comfortable living environment and, as a result, on the development of rural areas in the region are the objectives of this study.

The research object is rural territories of the mining region.

The research carried out using the methods of comparative, economic analysis and statistical method.

\section{Discussion}

If the traditional domestic practice of placing production within the boundaries of the city limits, to a greater extent affects rural areas indirectly, then in Kemerovo situation is different in a region with an intensive development of the industrial sector of the economy, the main of which is the mining industry. Kemerovo region is a mining region dominated by the coal industry, which includes numerous enterprises with open-pit coal mining. In 2018 , the region ranks first in the SFO in coal production, with a volume of 255.3 million tons, of which about 66 percent is open - cast.

Representing a region with a pronounced industrial specialization, Kuzbass has more than 45 thousand enterprises and organizations of various industry affiliations, and according to calculations, there is one enterprise per 17 square kilometers. More than half of them represent the coal, metallurgical, and chemical industries.

Industrial production inevitably accompanied by an increased load on the environment, emissions that pollute the air, water pollution, and the accumulation of industrial waste. The largest share in the total amount of environmental pollution made by the coal mining, metallurgical, and chemical industries.

Coal enterprises occupy large areas of land and, along with a negative impact on the environment, contribute to the degradation of arable land, including the storage of rock on them. High-intensity coal mining in the region, the consequences of a high degree of urbanization are accompanied by the presence of signs of land degradation, including its fertility, a decrease in the animal population, and therefore the loss of renewable natural resources[1;3;6].

Today, the level of environmental pollution in Kuzbass is on the 2nd place in the SFD, second only to the Krasnoyarsk territory, and air and water pollution kept at a high level. The specific climatic conditions and geographical location of Kuzbass caused the concentration of substances that pollute the air and do not disperse, but settle in the Kuznetsk basin, forming a smog of photochemical composition that has a negative impact on human health.

Coal production in the region is increasing annually, which leads to an increase in the alienation of agricultural land, usually highly fertile. According to experts, an average of 10 
hectares of land needs to be disturbed to extract one million tons of open-cast coal. It know that by extracting one ton of coal, the company generates 3-20 tons of rock mass, and 5-25 cubic meters of methane gets into the atmosphere. At the same time, due to mining operations, fertile lands are damaged and withdrawn from agriculture, small rivers and natural reservoirs are destroyed[5;9].

Coal industry enterprises are located in rural areas, and coal mining is economically more profitable than agriculture. "...from the point of view of the survival of the regional economy, creating conditions for the stable functioning of the social sphere, the development of the coal industry is economically justified, but at the same time, there are serious environmental problems that affect such an important component of the quality of life of the population as health. The health of the population is a kind of indicator of the socio-economic situation in the whole country and its individual regions", believes P. D. Kosinskiy [7].

As a result, in rural areas, over the past decades, the specialization of production has shifted from traditional agricultural activities to the dominance of the coal industry. The share of people engaged in mining in the total number of people employed in the economy in rural areas significantly exceeds agricultural production.

Along with such an important factor for ensuring a comfortable living environment as a balanced diet, one of the conditions for choosing a place of residence is the state of the environment, the possibility of its impact on a person, his health, which is an indicator of the quality of life of people.

Particularly difficult environmental conditions are the cities of Novokuznetsk, Mezhdurechensk, Belovo, mysky, Leninsk-Kuznetsky, Novokuznetsk, Leninsk-Kuznetsky, prokopyevsky, Belovsky municipal districts, where the largest part of coal mining operations is located. These territories characterized by the largest population, which accounts for $2 / 3$ of the total number of Kemerovo region.

At the same time, there is a decrease in the diversion of water runoff to waterways, which for the period from 2007 to 2017 decreased by 343.3 million cubic meters (by 42.8 percent). At the same time, there was an increase in the volume of runoff of standardtreated water by 30.7 times over the same period.

In the region, there is a steady trend of population decline of a declining birth rate and an increase in mortality. Thus, over the past five years (2014-2018), the region's population has decreased by 50.7 thousand people (1.86\%) [2] (table 1). It should be noted that this trend will continue in the near future. According to the calculations of demographers, if the current rate of negative population growth is not significant, the population in the region will decrease by 8 percent by 2035 .

Table 1. The Value of indicators that characterize the natural movement of the population in rural areas of Kuzbass in 2014-2018.

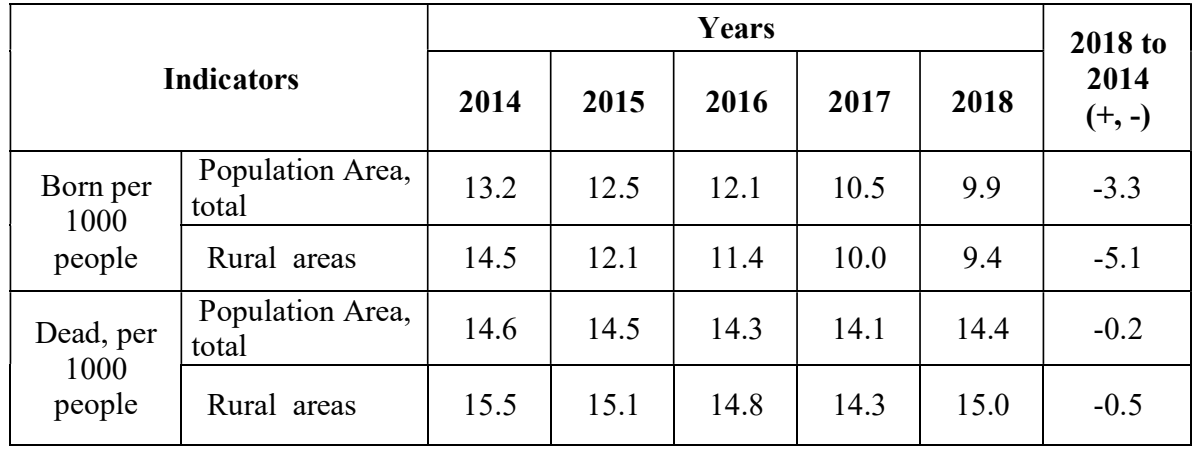




\begin{tabular}{|l|l|c|c|c|c|c|c|}
\hline $\begin{array}{c}\text { Growth } \\
\text { factors } \\
\text { (decrease) }\end{array}$ & $\begin{array}{c}\text { Population Area, } \\
\text { total }\end{array}$ & -1.4 & -2.0 & -2.2 & -3.6 & -4.5 & -3.1 \\
\cline { 2 - 8 } $\begin{array}{c}\text { on 1000 } \\
\text { people }\end{array}$ & Rural areas & -1.0 & -3.0 & -3.4 & -4.3 & -5.6 & -4.6 \\
\hline $\begin{array}{l}\text { Life } \\
\text { expectancy } \\
\text { at birth, } \\
\text { years }\end{array}$ & $\begin{array}{c}\text { Population Area, } \\
\text { total }\end{array}$ & 67.8 & 68.31 & 68.72 & 69.35 & 69.32 & 1.52 \\
\cline { 2 - 8 } & Rural areas & 66.0 & 67.1 & 67.6 & 68.3 & 68.26 & 2.26 \\
\hline
\end{tabular}

Rural areas, as can be seen from the table, are significantly inferior to regional indicators that characterize the birth rate, but at the same time, mortality and decline remain higher. Due to the high anthropogenic load on the environment of rural residents expressed by the volume of substances that produce stationary sources and polluting the air, in thousands of tons per thousand of the population in rural areas is 4 times higher than this indicator in urban areas in 2018). As a result, the life expectancy of a rural resident is less than in the whole region by 1.06 years[2;12].

In open-pit coal mining, not only the health of miners directly working at coal enterprises, but also the population of the entire region is affected. Open-pit coal mining contributes to huge emissions of coal dust into the atmosphere, which constantly inhaled by residents of rural and urban areas.

In 2018, emissions of pollutants amounted to 1618.3 thousand tons or 517.0 kilograms per inhabitant, 21.8 percent more than in 2014. Various substances that pollute the atmosphere have more than 200 types. As noted above, the greatest anthropogenic load is present in rural areas where there is intensive development of coal deposits. In the worst situation: Novokuznetsk district -5581, Leninsk-Kuznetsky -4568, Prokopevsky -2320, Belovsky -2256 kilograms per person. Various substances that pollute the atmosphere have more than 200 types.

Among them " ... highly toxic and carcinogenic substances in the form of soot, lead, carbon and nitrogen oxides. The structure of pollutants mostly contains elements that produced by stationary sources and are solid substances with a volume of 146.8 thousand tons. In addition, the volume of gaseous and liquid substances occupies 1340.8 thousand tons"[7]. Many experts directly link the growth of oncological diseases with adverse environmental condition[9; $11 ; 13]$.

This circumstance determines the need to develop and take measures to improve the current situation in the region, the implementation of which will significantly affect the improvement of the environmental situation in the region and, as a result, create a fairly comfortable environment for people, and therefore give rural areas a dynamic development. As one of the solutions, the authors propose a model of a comfortable living environment for people.

\section{Results}

Creating a model of a comfortable living environment for people, we will proceed from the circumstances that any environmental impacts will have consequences described using the formula:

$$
\mathrm{D}=\mathrm{Pp}+\mathrm{Ro},
$$

where: D-the action is equal to the product $\mathrm{Pp}$ plus the effects of $\mathrm{Po}$, then at least the ratio must be observed when $\mathrm{PP}>\mathrm{Po}$ and $\mathrm{PP}>\mathrm{D}$.

People making the choice of a place of residence evaluate the conditions that characterize:

a) factors of natural and climatic character, otherwise favorable habitat; 
b) the presence of factors that characterize the level of quality of life of the population;

c) development of agriculture that provides food for the population and food security;

d) conditions for recreation and tourism;

e) employment opportunities, ensuring employment of people.

Evaluating the rural territories of Kuzbass in terms of comfortable living conditions for people, we can conclude the following:

1. The region characterized by a favorable climate situation comparable to the city of Sochi in terms of the amount of sunshine. The availability of transport infrastructure allows people to travel within the region and the country. Favorable conditions for agricultural production, gardening, animal husbandry and beekeeping. All of the above gives reason to believe that in this part of the rural territories of Kuzbass are quite attractive to the population.

2. The development of the mining industry and other industrial sectors has created a complex environmental environment, the presence of negative man-made impacts on humans. As a result, people try to move to another area with a less stressful environment, which is one of the reasons for the decline in the population of the region. We emphasize that Kuzbass is characterized by heterogeneity of various levels of man-made zones.

3. The region's development determined by unique deposits of hard coal, including anthracites and brown coals, estimated at 700 billion tons. The current production rate can ensure this production within 600 years.

Based on this, the model by which you can choose a comfortable environment for people looks like this (1):

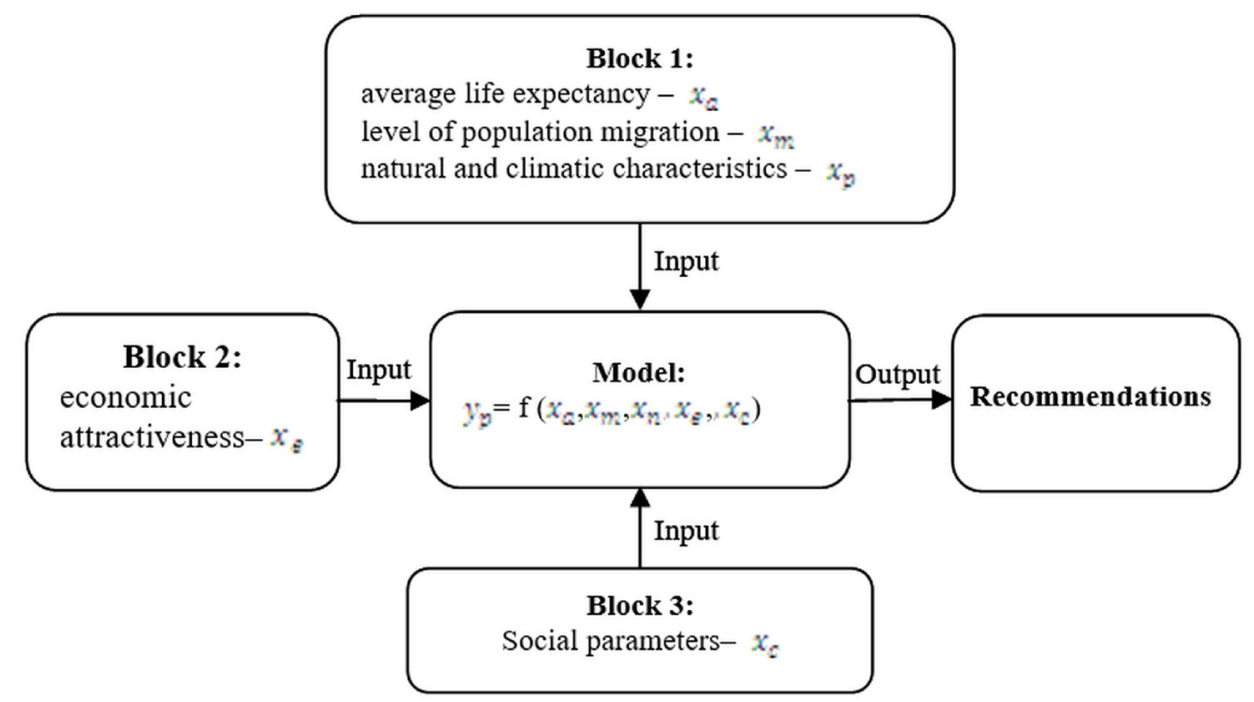

Fig. 1. Model of a comfortable human environment.

This model includes three systematic blocks: the vital factors of the territory represent the first block; economic factors form the second block and social factors form the third. In each block, you can define your own type of model, which will take into account all parameters. This model makes it possible to rank territories by calculating the average $y_{p}$ value of each element included in the sample. By calculating deviations from the average value, we can control parameters that differ by the maximum minus sign. Parameters whose impact is not manageable (for example, natural and climatic)can equate with social or 
economic regulated parameters, which will make it possible to improve a comfortable living environment.

The $\mathrm{X}_{\mathrm{a}}$ indicator describing the average life expectancy in years can calculate from statistical data. The attractiveness and comfort of the habitat for the population will be preferable to the territory with a longer life span. This does not take into account other factors, such as economic factors that also affect the comfort of the environment.

The following indicator $\mathrm{X}_{\mathrm{m}}$ shows the activity of migration processes, is measured as a percentage and characterizes the comfort of the habitat for the people of the territory and significantly depends on the above. As the outflow of population increases, the comfort of the environment decreases, and Vice versa.

The integrated $\mathrm{X}_{\mathrm{n}}$, indicator, which characterizes natural and climatic conditions and integrates into such factors as the average annual temperature, the number of Sunny days per year, etc. As this indicator increases, the comfort of the environment increases. For people whose territories have a warm climate will be more comfortable than with a cold one. The integral indicator is not regulate, because a person is not able to influence the climate globally. However, the construction of canals and ponds can mitigate the negative impact on a comfortable living environment.

The integral indicator also includes the economic attractiveness of $\mathrm{x}_{\mathrm{e}}$, which takes into account the level of average wages, employment, and the level of poverty. The economic factor can overcome the negative impact of natural and climatic conditions and significantly enhance the comfortable living environment for people.

The presence of educational institutions, culture, social benefits and pensions is characterized by the social factor $\mathbf{X}_{\mathrm{c}}$. This factor, in its absence or insignificant volumes, can, even with serious economic preferences, significantly reduce the comfort of the living environment of the territory.

The presented model of a comfortable living environment is universal and can not only to individual territories, but also to regional groups. The resulting calculations can eventually become the basis for making recommendations to improve the comfortable living environment through the impact on the regulated indicators.

\section{Conclusion}

Summarizing the above, we can conclude that the regional feature of rural areas of Kuzbass express in a significant impact on the living environment of environmental and economic factors accompanied by an increased level of morbidity, which is more than twice the average for Russia. Therefore, when developing regional programs for socio-economic development, state authorities need to keep in mind that people and their health are the main productive force. The consequences of the influence of environmental and economic factors are the morbidity of people with an increased level and accompanied by a low life expectancy, which ultimately reduces the population with a stable trend. The proposed model for determining a comfortable living environment makes it possible to assess the attractiveness of the territory when deciding on a future place of residence. In addition, the assessment of a comfortable environment allows you to make informed management decisions aimed at improving the quality of life of people. 


\section{References}

1. S. V. Bereznev, V. G. Mikhailov, Mining Informational and Analytical Bulletin, 12, 183 (2008)

2. Report on the State and Environmental Protection of the Kemerovo Region in 2018. URL: www.kuzbasseco.ru

3. N. Zaruba, N. Egorova, P. Kosinskij, E3S Web of Conf., 15, 04003 (2017)

4. N. Egorova, N. Zaruba, K. Dusan, E3S Web of Conf., 105, 02011 (2019)

5. N. Egorova, N. Zaruba, T. Jurzina, V. Tumin, E3S Web of Conf., 105, 02001 (2018)

6. T. V. Kiseleva, V. G. Mikhailov, V. A. Karasev, IOP Conf. Series: Earth and Environmental Science, 50, 012013 (2016)

7. P. D. Kosinskiy, International Journal of Applied and Fundamental Research, 6:3, 484 (2015)

8. M. Yazevich, O. Kalinina, O. Zhironkina, E3S Web of Conf., 134, 03004 (2019)

9. G. E. Mekush, Y. M. Elgina, Journal of Economy and entrepreneurship, 64-1:11-1, 327 (2015)

10. N. A. Zaruba, Economics and Innovation Management, 3, 17 (2018), DOI: 10.26730/2587-5574-2018-3-17-26

11. O. Nikiforova, T. Yakushina, R. Mamedov, E3S Web of Conf., 105, 04013 (2019)

12. Environment/Kemerovostat Internet Portal. URL: kemerovostat.gks.ru

13. P. Kosinskiy, V. Merkuriev, A. Medvedev, E3S Web of Conf., 134, 03009 (2019)

14. T. Jurzina, N. Egorova, N. Zaruba, P. Kosinskij, E3S Web of Conf., 21, 04010 (2017)

15. T. A. Yurzina, N. N. Egorova, Journal of Economy and entrepreneurship, 85:8-1, 380 (2017) 